ISSN 1936-5098

CAE Working Paper \#09-11

A Simple Model of the Financial Crisis of 2007-9 with Implications for the Design of a Stimulus Package

by

Kaushik Basu

August 2009 
August 15, 2009

\title{
A Simple Model of the Financial Crisis of 2007-9 with Implications for the Design of a Stimulus Package
}

\author{
Kaushik Basu \\ Department of Economics \\ Cornell University \\ Ithaca, NY 14853 \\ Email: kb40@cornell.edu
}

\begin{abstract}
The financial crisis of 2007-09 began as a local problem in the mortgage finance market in the United States and Europe but, within months, escalated into a general global financial crisis, resulting in collapsing investment not just in developed nations but also in Shanghai, Rio and Mumbai, and has led to a general recession worldwide. The paper builds a rational-expectations, microeconomic model of why the local crisis escalated into a general freeze in credit flows. It then isolates two very different kinds of interventions needed to restore the economy back to health, arguing that government stimulus policy has not had enough impact because a failure to understand the need for the dual intervention.
\end{abstract}

Key words: financial crisis, recession, multiple equilibria, credit markets, credit ratings

Acknowledgements The paper was the subject of the Montreal Economic Theory Lecture, delivered on May 8, 2009 at Concordia University, Montreal. It was also presented at the conference on the Microfoundations of Development at the London School of Economics, May 30, 2009, and at the Centre for the Study of Social Sciences, Calcutta, on August 4, 2009. I am grateful to the participants at these meetings and also to Sugato Bhattacharyya, Philip Bond, Brian Dillon, Massimo Morelli, Debraj Ray, and Jorgen Weibull for helpful suggestions. 


\section{A Simple Model of the Financial Crisis of 2007-9 with Implications for the Design of a Stimulus Package}

\section{Introduction}

The aim of this paper is to provide a grammar for dissecting the financial crisis that began in the housing finance market of industrialized nations in 2007, rapidly becoming a general credit crisis and spreading to all parts of the world and causing a global recession of gigantic proportions. The unexpectedness and force of the crisis has had experts floundering for an explanation and the policy response has been an ad hoc collection of stimulus interventions by governments and central banks around the world, akin to scatter shots in the hope that some will hit the target whatever it be.

The proximate cause of the crisis is reasonably well understood. It began with the subprime mortgage crisis in the U.S. Sub-prime lending, that is, mortgages given to borrowers who do not meet the credit standard cut-off for government-sponsored enterprises ${ }^{1}$, rose steadily from just below $\$ 100$ billion in 1996 to around $\$ 600$ billion in 2006. In 2006, sub-prime lending constituted a whopping $22 \%$ of all mortgages issued in the U.S. (Coval, Jurek and Stafford, 2009). As was to be expected, this resulted in a rise in the default rates among home loan borrowers, first noted in February 2007 and fully evident by August that year. As this happened and more homes came on the market, prices of homes began to fall. From mid-2006 to mid-2008 house prices in the U.S. fell at the rate of 10\% per annum (Mayer, Pence and Sherlund, 2009). This in turn meant that lending banks and financial institutions found their asset position weakening, since the values of the foreclosed homes were now less than when the mortgages were signed. Soon these institutions were, in turn, defaulting on their loans. As this fear spread, inter-bank and inter-corporate lending came to a virtual standstill.

This sketchy story is a valid one but it is highly incomplete and with glaring open questions. Why, for instance, would $i$ cease to lend to $j$, just because $y$ did not get repayment for

\footnotetext{
${ }^{1}$ A sub-prime borrower is often defined by the borrower's "FICO score", that is, a credit rating that is based on the repayment record of the previous six months, developed by Fair Isaac and Company, or FICO. In the absence of other redeeming factors, a score of less than 660 makes the borrower sub-prime.
} 
a loan he had given to $x$ ? After the sub-prime defaults go down, why does the economy not go back to the original equilibrium on its own steam? If to revive the credit market, we need the government to inject demand into the economy, how long does that have to be sustained? By late 2007, the European Central Bank, the U.S. Federal Reserve and, after some initial hesitation, the Bank of England, began injecting liquidity into the money market. On December 17 and 20, 2007, the U.S. Fed in collaboration with several other banks, including the Swiss National Bank and the Bank of Japan, auctioned $\$ 40$ billion worth of loans of one-month duration and followed this up later with more such auctions. Yet all this action seems to have had only "a marginal impact" on the problem (see Rakshit, 2008). Why was that so? Why was the eventual crisis so much larger than the primary shock?

The aim of this paper is to fill in not all but some of the most critical gaps in our understanding of this financial crisis and to answer a few of the questions that continue to confound us. While my analysis is not meant to provide a final answer - with such a major event no single paper can aim for that - it highlights some of the most critical elements of the crisis. Further, by doing so, we are able to think much more analytically about what the policy response ought to be. It gives us a structure for thinking about how a stimulus package ought to be designed, the alternative interventions which can lift the economy back to the good equilibrium and, if government has to inject money into the system, how long this needs to last.

The formal model is simple; it hinges critically on taking some complex pieces of reality and converting them into uncomplicated, manageable assumptions. The paper makes no claims to theoretical novelty. The aim here is to draw on some existing ideas concerning equilibria where group behavior influences individual preferences, and which give rise to multiple equilibria. Unlike several other works, the model in this paper does not try to explain the collapse in terms of the bursting of a bubble. In the analysis of credit and banking there have been important works on the role of multiple equilibria (Diamond and Dybvig, 1983; Chamley, 2003) and how small shocks can escalate into major disturbances (see, for instance, Kiyotaki and Moore, 1997). In terms of modeling technique, the closest work is Lindbeck, Nyberg and Weibull (1999). What makes the present exercise relevant and, hopefully, interesting is that the assumptions used arise very naturally in credit markets and the model maps naturally into some of the structures used in the modeling of social stigma. Of course, in fitting the credit crisis of 2007-09 into a mathematical structure I have to cast aside some complications of the real world, 
and the worth of the model will depend on how the bits of reality that are retained as building blocks are selected. This act of choice will be evident in the pages that follow. The next section describes the essential features of reality that are used here. Sections 3 and 4 describe the main mathematical model, section 5 discusses its policy implications and sections 6 consists of some concluding remarks.

\section{Ingredients}

Most lay observers do not understand the ubiquity of credit and lending and the close connection between these and a nation's output and productivity. Everybody understands that home-buyers take loans, at times very long ones, to be repaid over 30 years. Poor farmers take credit to buy seeds and fertilizer which they try to pay back after harvest. Consumers often use their credit cards to buy durable goods like cars and refrigerators. These are the obvious cases. But there are lots, maybe more, cases where credit is involved in non-obvious ways. There are very few transactions in life that are simultaneous. In restaurants you typically eat your food first and then pay. This means that, effectively, you take a short-duration loan from the restaurant. When you have your home painted, you either pay first and then have the home painted or do it the other way around. In either case, a credit transaction occurs - either you give a week-long loan to the painter, which she repays steadily over the week (by doing the painting job), or she gives you a stream of credit over a week which you repay at the end of the week. Credit is germane to international trade. Usually the supplier receives payment in advance (often even before the product is fully ready) and then ships out the product. Even if the sequence is reversed, whereby the importing nation pays after the goods are received, as is occasionally the case, the claim of an implicit credit transaction remains unchanged. It is interesting that the first wave of the global crisis washed ashore in India in the form of a worsening of this kind of trade credit. The length of time taken to pay Indian exporters began increasing and, for many small exporters, this was a death knell.

It is immediately obvious that, if expectations that loans will be repaid break down, then there can be a huge drop in productive activity. Restaurants may close down or hire expensive henchmen to guard doors. Houses may not get painted and trade can stutter and come to a virtual halt. A financial crisis then spills over into a recession causing a downturn in actual 
production, as happened with the financial crisis that began in 2007. The hardship is being felt not only in the industrialized world where the crisis began but also in the developing countries (see Lin, 2008; Ocampo, 2009; Subbarao, 2009; Boorman, 2009). The escalation to economies that may have had nothing to do with the origins of the crisis is somewhat reminiscent of the East Asian crisis of 1997 (Basu, 2003), but the causation in this case, as will be argued below, is very different.

A second critical ingredient of my analysis is that when a bank or a firm or an investment company or an individual considers giving credit to some person or bank or corporation which is to be paid back not in an hour or two (as in a restaurant) but in a few days or weeks or years, the lender will not only make projections about the economy and the borrower's future income and wealth but also at the borrower's overall credit-worthiness. This is because when a ponzi is run purely as a ponzi, as Bernard Madoff did, it is criminal and, fortunately, rare. But ponzis that get woven into the fabric of legitimate business activities are common ${ }^{2}$. A firm issues bonds to raise money to invest in a new project. The project succeeds only partially and, when the time comes for repayment, the firm is not in a position to repay the bondholders. It is common for such a firm to take another round of credit from others and payback the first group of lenders. The legality of such an action can be questioned, since this is effectively a step towards a Ponzi. Yet this practice is common among corporations and even nations. Hence, the borrower's creditworthiness and access to credit in general is important to you when you extend a loan to the borrower.

A third ingredient of my analysis, closely related to the previous one, is the recognition that how creditworthy a particular borrower is depends on the characteristics of the borrower but also on the aggregate lending activity in the economy. If aggregate credit dries up, then the same borrower, in the otherwise same state of the world, may not be viewed as creditworthy. As Shin (2009, p. 102), commenting on the run on Northern Rock in the United Kingdom in September 2007 (even though it had very little exposure to risky lending), remarks, "Although Northern Rock had virtually no subprime lending, it was nevertheless fishing from the same pool of shortterm funding." It is this idea of "fishing from the same pool" that will play an important role in the model that is constructed in this paper.

\footnotetext{
${ }^{2}$ Shiller (2000) talks about "naturally occurring Ponzis". I have argued elsewhere how one can camouflage Ponzis by building these into legitimate marketing strategies (Basu, 2009). The analogy of the Ponzi-like character of the current housing crisis has been discussed by Hockett (2009).
} 
Finally, it is important to clarify a feature of the 'limited liability' clause so widely used in business transactions. Essentially this means that there is a limit to how impoverished a lender can leave you in trying to reclaim his loan. On this there are important differences in the law. In the U.S. home loans are generally non-recourse debts, though there are important inter-state differences (Pence, 2006). In the event of a default, the lender can take away the collateral, in this case your home, but not your car, watch and money in the bank. In the event of the mortgage being recourse, banks giving mortgage can confiscate other (that is non-home) assets of the borrower in trying to recover the full value of the loan. The fact of home loans being nonrecourse can exacerbate the adverse selection problem and cause inefficiencies. But in the present context, the recourse characteristics of the loans are not factors of any special significance. What is important to recognize in the context of the model being built here is that, while the extent of liability varies across societies, there is really no such thing as full liability. This is because, in the end, people can be reduced to a condition where they have nothing more to offer. For this reason, when a poor person takes a large loan there is automatic limited liability no matter what the law of the nation says.

\section{Model}

Suppose there exist $n$ banks or financial institutions or firms who are able to lend money. They will be referred to here as 'lenders'. Each lender has to decide whether or not to lend money and, if yes, how much to lend. This will determine the aggregate supply of credit of credit in the economy. The ultimate equilibrium will depend on supply and demand for credit. I will get to deriving an equilibrium eventually but since the focus of this paper is on the behavior of banks, financial institutions, and other lenders, I shall first develop the supply side story and do so somewhat elaborately.

If the going market interest rate is $r$ and a lender $i$ lends $L_{i}$ dollars, then the lender is supposed to get back $(1+r) L_{i}$ dollars. But there can always be some risk of default. Let us use $p$ to denote the probability that the loan will be repaid. For reasons of mathematical simplicity I will assume that this is a $0-1$ event. That is, with probability $p$ the entire loan is repaid, and with probability $(1-p)$ nothing is repaid. An alternative approach that works equally well involves treating $p$ as the fraction of the loan that the lender expects to recover. 
$p$ depends on numerous factors. As discussed in the last section, most nations provide some kind of limited liability cover to borrowers. That is, if the project for which the borrower takes credit fails, there is a limit beyond which the lender is not allowed to go in recovering the loan. In most U.S. states, either by law or by practice, home mortgage loans are largely "nonrecourse". That is, if a borrower fails to pay back his mortgage, the lending bank can foreclose on the home but nothing else. Suppose that house prices collapse, as actually happened in the sub-prime crisis, so that foreclosing on the home still does not cover the full value of the loan, in the U.S. the lender has to generally live with this loss. The lender cannot take away money from the borrower's checking account. This being so a borrower will have an incentive to walk away from a newly-purchased home and stop paying the mortgage, if its market price for homes drops sharply. The house will be foreclosed by the bank but he still benefits by defaulting. Hence, in such a legal regime (that is with where mortgage is non-recourse) $p$ will be lower. There are more states of the world where defaults will occur. Clearly, the precise nature and extent of the limited liability cover and legal regime, in general, will have a big influence on the value of $p$ and through this on lending behavior (see Haselmann, Pistor and Vig, 2009).

I shall have occasion to return to this later. For now, let $x$ denote the bundle of all exogenous variables which can influence $p$. If we want to make this lender-specific-even though there is no gain in generality by doing so, we would write this as $x_{i}$.

As already discussed, it is not uncommon for firms or individuals who face problems in paying back a loan to take another loan to pay back the first one. One sees this with individuals trying to pay back credit they may have taken for a car or a home, firms struggling to repay their bank loans and nations working to pay back money to international lenders, for instance, Peru in 1983 (Cline, 1984; Basu, 1991). This means that $p$ will depend in part on the aggregate amount of credit, $a$, that is supplied to the market.- If this dries up, firms will be less likely to repay your loan. Hence we shall from now on assume:

$$
p=p(a, x)
$$

where $\frac{\partial p(a, x)}{\partial a}>0$

When lender $i$ gives credit equal to $L_{i}$ dollars, it incurs costs. In case it lends money by using its internal resources, there is the cost of foregone interest earnings. If it raises money from the market, there will be direct interest costs. Moreover, the extent of money that a firm can 
lend depends on its own asset position (Aghion, Bacchetta and Banerjee, 2000). We can mimic this by supposing that the cost of lending each dollar goes up as the firm considers lending more and this happens more sharply the smaller is the asset base of the lender. We will simply assume that total cost incurred by a lender is $c_{i}\left(L_{i}\right)$. Further, to keep the algebra simple, I shall assume that these functions take the following form. For each lender $i$,

$$
c_{i}\left(L_{i}\right)=c\left(L_{i}\right)+\alpha_{i}
$$

where $c^{\prime}>0, c^{\prime \prime}>0, c(0)=0$.

Without loss of generality, assume $\alpha_{1} \leq \alpha_{2} \leq \ldots \leq \alpha_{n}$. In other words, lender 1 is the most efficient, lender 2 the second most efficient and so on (with ties broken arbitrarily).

Lender i's profit function is, therefore, given by:

$$
\pi_{i}=p(a, x)(1+r) L_{i}-c\left(L_{i}\right)-\alpha_{i} .
$$

The first-order condition for maximizing profit is the following:

$$
p(a, x)(1+r)=c^{\prime}(L)
$$

It is fine to suppress the subscript $i$ from $L_{i}$ since this will be the same for all lenders. So, if lender $i$ chooses to lend money, she will lend the $L$ dollars implicitly given by (4). The value of $\alpha_{i}$ influences the decision whether to lend at all or not. But once a lender decides to lend the amount lent does not depend on $\alpha_{i}$.

Using $\phi$ to denote the inverse function of $c^{\prime}$, (4) may be re-written as

$$
L=\phi(p(a, x)(1+r)) .
$$

Given $a, x$, and $r$, it is simple to check how many lenders will be active in the credit market. Denote by $\alpha^{*}$ the value of $\alpha$ that solves the following implicit function.

$$
\underset{L}{\operatorname{Max}}[p(a, x)(1+r) L-c(L)-\alpha]=0
$$

Alternatively, $\alpha^{*}$ is defined by

$$
p(a, x)(1+r) \phi(p(a, x)(1+r))-c(\phi(p(a, x)(1+r)))=\alpha^{*}
$$

It is worth keeping in mind that $\alpha^{*}$ depends on $a, x$, and $r$. It is now evident that, given $a, x$ and $r$, every firm $i$, such that $\alpha_{i}<\alpha^{*}$ will choose to lend money. Define $m(a, x, r)$ to be the largest integer $m$ that satisfies the inequality:

$$
\alpha_{m}<\alpha^{*}
$$


It follows that for every $a, x$ and $r$, lenders $1,2, \ldots, m(a, x, r)$ will be lending money; and lenders $m(a, x, r)+1, m(a, x, r)+2, \ldots, n$, will choose not to enter the credit market, that is, not to lend money.

We have thus far treated $a, x$ and $r$ as exogenous. While to each single firm these are indeed exogenous, we would expect $a$ (the total lending) and $r$ (the interest) to be endogenously determined by the market. It is the determination of these variables that we must now proceed to describe.

Suppose $x$ and $r$ are given and the expected aggregate supply of credit is believed to be $a$. It is straightforward to derive what the actual aggregate supply of credit will be. This is given by $m(a, x, r) \phi(p(a, x)(1+r))$. If we use $A$ to denote the actual, aggregate supply of credit, we have

$$
A=m(a, x, r) \phi(p(a, x)(1+r))
$$

We are now in a position to define one feature of the equilibrium. Observe that the actual aggregate supply of credit, $A$, depends on the expected aggregate supply of credit. Given $x$ and $r$, we shall say that the aggregate supply of credit, $a^{*}$, satisfies 'rational expectations' if

$$
a^{*}=m\left(a^{*}, x, r\right) \phi\left(p\left(a^{*}, x\right)(1+r)\right)
$$

What I have just described is the standard idea of a rational expectations equilibrium. In the abstract this same idea of equilibrium has been used in several other works such as Basu (1991) and Lindbeck, Nyberg and Weibull (1999), which, in turn, reflects some early ideas of how group outcomes may influence individual preferences (Besley and Coate, 1993).

It is useful to graphically describe what we have done thus far. Note that $A$ as a function of $a$, as described by equation (8), is an upward-sloping function. As $a$ increases, $p(a, x)$ increases (by assumption). Since $c^{\prime \prime}>0, \phi^{\prime}$ must be greater than 0 . Hence, as $a$ increases, $L$ (in equation 5 ) must rise. It is easy to check that $m(a, x, r)$ rises with $a$. Hence, as $a$ increases, $A$ must rise. Figure 1 depicts an interesting case of this graph. This is shown by the S-shaped curve, $B D$. There are many assumptions that could give rise to this shape, such as certain distributions of the $\alpha$ 's across the lenders.

In the case depicted in Figure 1 there are three levels of aggregate credit supply that satisfy rational expectations; these occur at points $a_{1}, a_{2}$ and $a_{3}$. That is, if $x$ and $r$ are such that function (8) gives rises to curve $B D$, then aggregate credit supply will stabilize at one of three possible levels, $a_{1}, a_{2}$, and $a_{3}$. Each of these expected supply results in an actual supply equal to the expected supply. 
Our next step is to explain the determination of the interest rate, $r$. Note that, if $r$ increases, the graph BD will move to the upwards, or, equivalently, leftward. This is because, a rise in $r$, increases both the number of lenders and the amount each lender lends, that is, respectively, $m(a, r)$ and $\phi(p(a, x)(1+r))$. It follows from (8), the value of $A$ must rise.

\section{Figure 1}

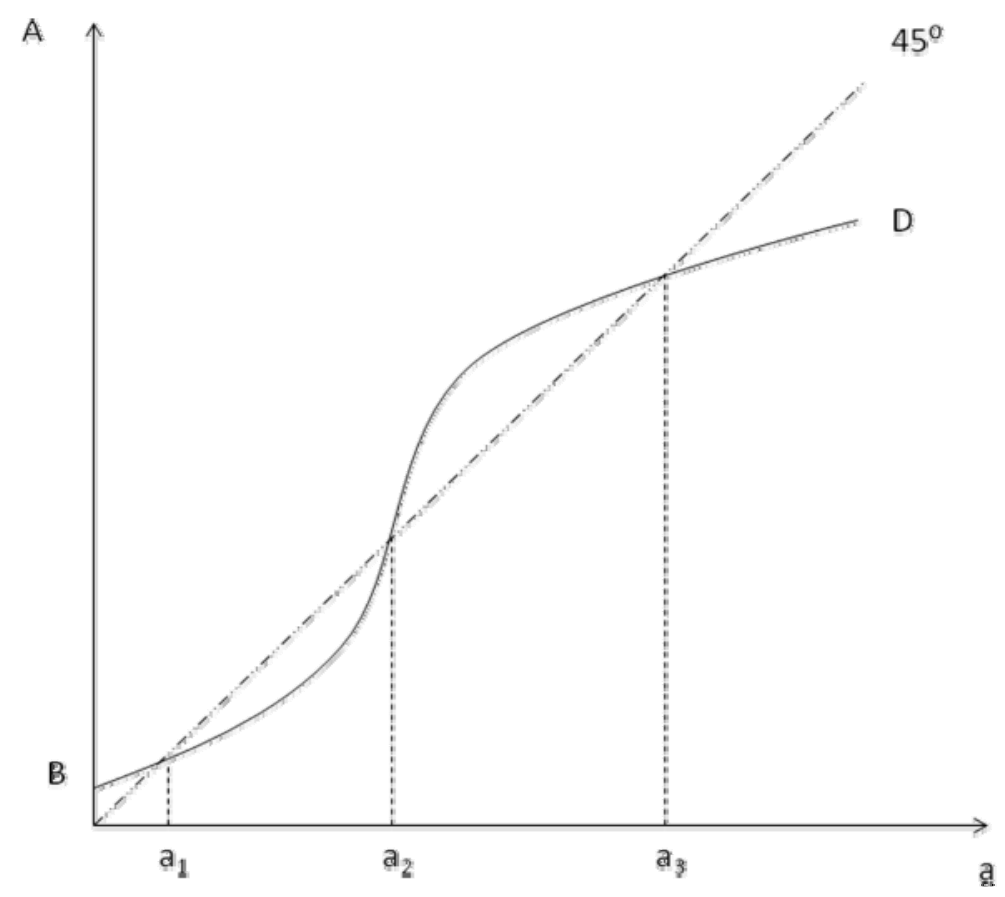

Now, by varying $r$ and plotting the values of $a$ which have the rational expectations property, for each $r$, we can derive the 'supply correspondence'. I shall call this $S(r)$. This shows all the possible supplies of aggregate credit that have the rational expectations property, for each interest rate $r$. This is easily derived in the case illustrated in Figure 1, and is shown in Figure 2, as curve $S$.

To understand the derivation of the $S(r)$ correspondence shown in Figure 2 suppose the interest rate implicit in the graph shown in Figure 1 is $r^{l}$. In Figure 2, mark the point $r^{l}$ on the vertical axis, place a horizontal ruler exactly through that point and mark the three points that satisfy rational expectations for $r^{l}$. That is, mark $a_{1}$ (as shown), $a_{2}$ and $a_{3}$ (not shown). Next, lower $r$ to $r^{2}$. In Figure 1, the graph BD will move down and as a consequence the points $a_{1}$ and 
$a_{2}$ will move further away from each other and $a_{3}$ will move to the left. Again, in Figure 2, hold a horizontal ruler through $r^{2}$ and mark the three points where credit supply satisfies rational expectations. Continue to do this for different interest rates and all the points thus marked when joined up will look like the graph S shown in Figure 2. That is the supply correspondence $S(r)$.

\section{Figure 2}

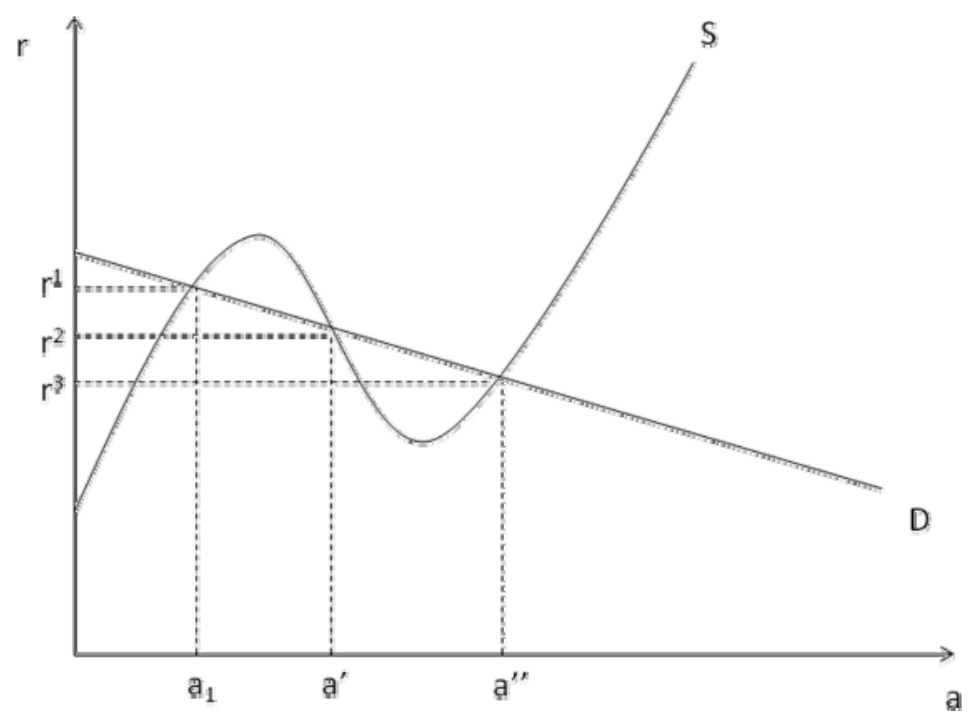

To derive the interest rate endogenously and describe the full credit market equilibrium all we need to do now is to bring the demand for credit into the picture. In order to keep the analysis simple, let me simply assume that the aggregate demand for loans or credit, $D$, increases, as the interest rate declines. Hence,

$$
D=D(r), D^{\prime}(r)<0
$$

Following standard textbook analysis, we shall describe an 'equilibrium' to be an interest rate $r$, such that there exists $s(r) \in S(r)$, so that

$$
D(r)=s(r) \text {. }
$$

If $r^{*}$ is an equilibrium, then $D\left(r^{*}\right)$ or $s\left(r^{*}\right)$ is the equilibrium volume of credit that is transacted in the market.

It should be obvious from the analysis above that the credit market can have multiple equilibria. This is illustrated in Figure 2. The possibility of multiple equilibria has given us 
many useful insights in development (Hoff and Stiglitz, 2001) and also in finance (Chamley, 2003 ) and, in fact, has been suggested by Kotlikoff (2009), as a clue to understanding the current crisis, even though Kotlikoff does not offer a formal model. And this is the line that is being pursued in the present paper.

This credit market can stabilize at interest rate $r^{1}, r^{2}$ or $r^{3}$ with varying levels of credit being transacted on the market. At the equilibrium $r^{3}$ in Figure 2 the credit market is very active, with a large amount of credit, $a^{\prime \prime}$, changing hands. On the other hand, if the market settles at equilibrium interest rate $r^{l}$, the supply of credit, $a_{l}$, will be much smaller. Let us suppose the economy has settled down at the high credit equilibrium with interest rate $r^{3}$. The next question that will be studied is how and why this equilibrium may break down.

\section{Breakdown}

One key ingredient for understanding credit market breakdowns is to figure out the meaning of a drop in the supply of credit. Essentially we want to see, if there is an exogenous change that makes it less attractive to give loans, how this affects the aggregate supply correspondence of credit. The logic is unchanged whether we study a fall or a rise in the supply of credit; so let me here explain the effect with the case of a rise. Suppose the exogenous variable $x$ changes in such a manner that $p$ in (3) is higher for every value of $a$. Clearly, each lender will now want to lend more. This is obvious from (4) and the fact that $c^{\prime \prime}>0$. It is easy to track the effect of this through the model and check that this causes the supply correspondence to move down (and not to the right as we may, at first blush, suppose).

That is, if the original supply correspondence was $S$ in Figure 3, when individual propensity to lend increases (because, for instance, $p$ increases), the correspondence shifts to $S$ '. What is important to note is that, given the dynamics of inter-lender behavior, this implies that the $S$ curve actually moves left in some segments (in particular where it is falling).

Suppose now that the original supply correspondence is given by $S^{\prime}$ and the demand function by $D$ in Figure 3. There are multiple equilibria, but suppose the economy is settled at $E^{3}$, where $S^{\prime}$ intersects $\mathrm{D}$. The interest rate is low and the supply of credit is plentiful.

Now assume there is a small exogenous shock which causes supply of credit to fall a little. This causes the supply correspondence to shift up to $S$. In the model that has been 
described here, this can have a dramatic effect on the credit market since this may result in several prior equilibria, in particular, the high-activity equilibrium, to disappear.

\section{Figure 3}

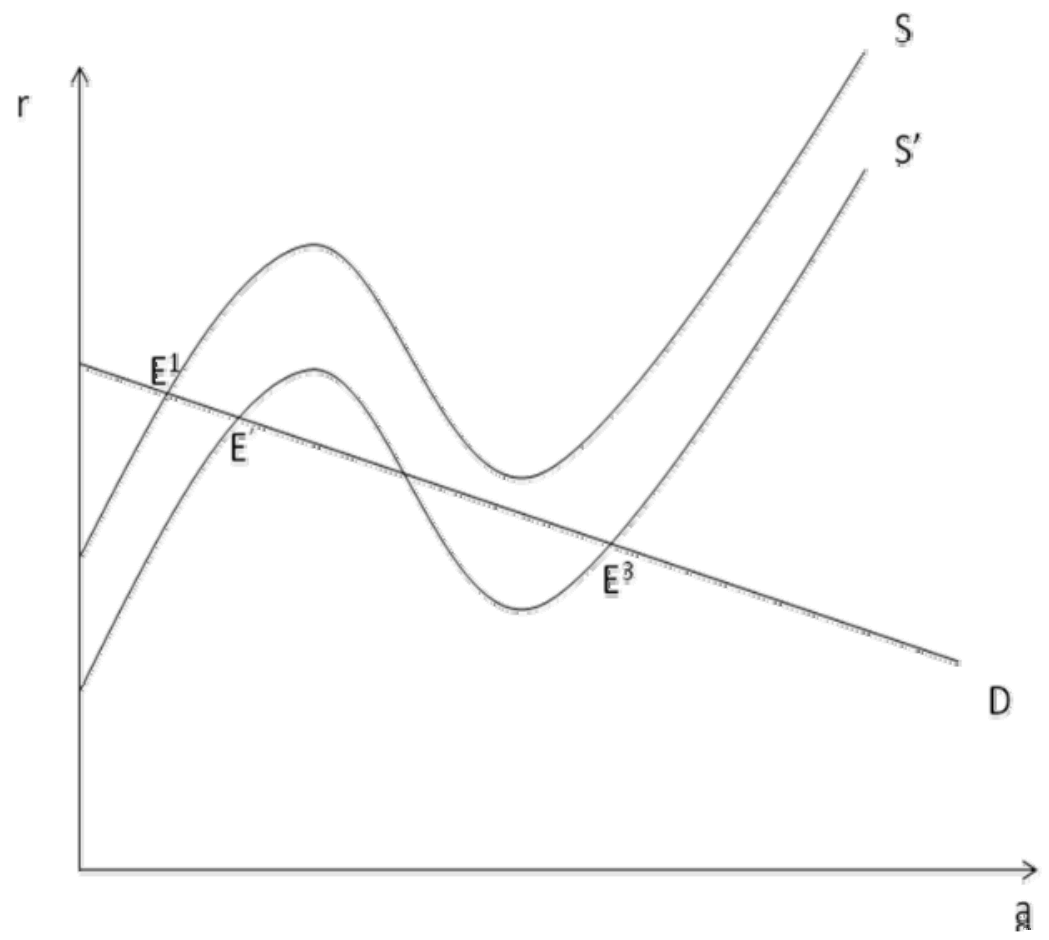

This is exactly the case described in Figure 3. After the small decline in supply there is a large tumble-down affect and the economy moves to the only equilibrium that exists in the new situation, at $E^{l}$. There is a collapse in credit availability, and a rise in the interest rate. ${ }^{3}$ In abstract terms, this is what happened in the current financial crisis. The original equilibrium was at $E^{3}$. A small shock caused a small decrease in credit supply, thereby triggering a large cascading movement in the equilibrium.

What kinds of small shocks can trigger off such a process? The answer is numerous. Suppose one lender discovers that, as a consequence of some prior decisions that it had made (for instance, lending to sub-prime home buyers), its asset position is worse than it thought. Let us suppose that this happens to the least efficient lender that was lending in equilibrium $E^{3}$. That

\footnotetext{
${ }^{3}$ The latter can be muted by central bank action. If the demand curve is horizontal or upward sloping (because of, for instance, government action), we can have a collapse in aggregate credit along with a constant or even declining interest rate. This would happen if the demand curve passes through point $E^{3}$ but happens to be horizontal or upward sloping.
} 
is, lender $m(a, x, r)$, where $a$ and $r$ refer to the aggregate lending and the market interest rate that prevail in equilibrium $E^{3}$, suddenly discovers that $\alpha_{m(a, x, r)}$ is larger than it had earlier supposed. This higher cost may result in this lender closing shop and ceasing to lend. This, in turn, lowers the aggregate amount of lending occurring in the economy (and cause an upward shift in the aggregate supply correspondence of credit). This may, in turn, cause the second least efficient lender, $m(a, x, r)-1$, to close shop, and then the third, and so on till the total lending activity collapses to $E^{l}$.

What in reality could have caused the first one or two lenders to suddenly find their asset position worse than they had anticipated? One answer lies in an interesting coordination problem among lenders. In the above model, for the most, it was assumed that, when there is no default, the lender gets back the full loan with interest and, in the event of a default, it gets back nothing. In reality, when there is default the lender can foreclose on the property. Interestingly, there has been some discussion within the FTC that some lenders lend precisely in the hope of foreclosing on property (that is, the hope that the borrower will default), a phenomenon that is often called 'predatory lending. ${ }^{4}$ Whether or not this is true, foreclosing does lead to the recovery of some asset and so, strictly speaking, the lender's profit, (3), should be written as $\pi_{i}=p(a, x)(1+r) L_{i}+(1-p(a, x)) F-c\left(L_{i}\right)-\alpha_{i}$, where $\mathrm{F}$ is the value of the property that is mortgaged for possible foreclosure.

As more and more lenders indulged in subprime lending, the share of risky borrowers rose. Not surprisingly, with a little lag, defaults rose. As this happened and more and more houses came back on the market, the value of houses declined. So the value of $F$, with which individual lenders had begun their calculations, declined. Clearly, the value of $F$ depends on how many others were indulging in sub-prime lending. If this aggregate supply was forecast wrongly, some firms would end up discovering that their asset position had weakened since the foreclosed property did not have the value that they had originally based their calculations on.

Another source of initial shock could be this. We do know that thanks to structured finance, whereby mortgages of different kinds were pooled together and then separated out into different tranches,--senior ones that have prior claim on money and so lose money only when a sufficiently large number of mortgages default and junior ones that take the initial blow (see

\footnotetext{
${ }^{4}$ See, for instance: http://www.ftc.gov/os/2000/05/predatorytestimony.htm. Interestingly, some early work in development economics made critical use of this idea in explaining some of the worst practices in rural moneylending (Bhaduri, 1977).
} 
Brunnermeier, 2009; Coval, Jurek, and Stafford, 2009)—ordinary investors and even sophisticated firms were not being properly able to evaluate risk $^{5}$. Suppose that one firm overestimates the probability, $p$, of getting back money. If this lender, after making corrections on this (that is, lowering $p$ ) decides not to lend anymore money, aggregate lending, $a$, will decline a little, and this can again shift the supply correspondence up and cause a breakdown in the credit market. In relying on this as a cause for the breakdown, it is important to go deeper into why firms and investment banks that were buying these collateralized credit obligations (CDOs) found it so difficult to properly calculate risk. Pooling mortgages of different risk or going a step further and pooling CDOs into higher order CDOs (called $\mathrm{CDO}^{2}$ ) do complicate matters but the buyers of these assets are sophisticated agents and it is unsatisfactory to leave this matter with the wave of a hand.

One interesting feature of structured finance can give us a deeper insight. In earlier times, credit ratings by rating agencies, such as Standard and Poor's or Fitch, have rated whole companies or even nations. So when debt issued by some company was given a rating AA+ the lender knew that this company's quality rating was somewhere in the interval from $\mathrm{AA}+$ to just below AAA. Once CDOs came into fashion, investment banks started creating new combination assets that were deliberately aimed at certain ratings. This tranche will be A-, this one AAA, and so on. Note that this mixing, matching, and splicing allow the creation of assets which only just make the mark of a certain rating. Indeed, since the demand for these CDOs depends on the ratings, it is never worthwhile creating tranches that lie in the middle or upper end of a 'rating interval'. In other words, these new securities were almost invariably clustered at the bottom cut off of each interval.

It is arguable that many agents buying these assets failed to recognize this change that had occurred as a consequence of structured finance. They were used to treating an AA+ asset as an asset somewhere between the start of AA+ and just below AAA. But with the arrival of CDOs that was no longer the case. The average quality of assets in each rate category was invariably at the bottom end of the interval. In other words, there was 'rate inflation' the way some universities have had grade inflation. And just as happened in the early days of grade inflation,

\footnotetext{
${ }^{5}$ While I am telling this story with fully rational agents, it is entirely possible that some of these mis-judgments are caused by deliberate tricks and psychological propensities that an investor's mind plays in encouraging him or her to 'play' the game (Akerlof and Shiller, 2009). What is interesting is that this tiny psychological 'mistake' can in this model cascade into a large consequence.
} 
buyers of these assets were slightly deceived ${ }^{6}$. In the world of finance, a small mistake per asset of this kind can amplify into big errors and, as my model shows, given the complicated interdependencies in this market among lenders the total impact can be vastly amplified, as happened in 2007 and 2008.

Standard and Poor's has recently introduced a new rating system specially designed for East Asian nations, with the aim of helping the growth of regional investment and credit markets. One significant change in this new rating system is the introduction of greater 'granularity' in ratings. This should go some distance in rectifying this problem since there will now be less space within each rating category and so, less room for rate inflation.

Finally, the initial shock can be the result of a 'correction' after a period of 'exuberance.' Suppose, triggered by some short-run phenomenon, there is an increase in the supply of credit. The supply correspondence in the above Figure, for instance, rises beyond S' (that is, moves down) for this reason of exuberance. This pushes the equilibrium credit to a little higher than $\mathrm{E}^{3}$. When this exuberance dies down or is corrected and the supply moves down to the original one, there can be an over reaction, which sends the equilibrium lending activity tumbling down in the manner described above.

In the presence of multiple equilibria, which equilibrium actually occurs is, by its very nature, a mystifying problem--one that defies formal analysis. All that theory can do is to locate the set of possible outcomes as we have done above.

All this brings me to the policy question. If, indeed, something like the above story is what caused the financial recession of 2007-9, what should our policy response be?

\section{Policy}

Suppose the credit supply declines and as a consequence the market breaks down and the economy goes to equilibrium $\mathrm{E}^{1}$ in Figure 3 . The main policy question is: how to get the economy back to the original equilibrium $\mathrm{E}^{3}$. As is obvious from the diagram, there are two quite distinct tasks involved. First, we need to increase the supply of credit, that is, to push the supply correspondence back to $S^{\prime}$ or close to S'. But that, in itself, is unlikely to be enough. As the

\footnotetext{
${ }^{6}$ As Lin $(2008$, p. 7) writes, “... these new securitized financial products with layers of underlying assets were revealed to be far riskier than their credit ratings indicated."
} 
supply correspondence gradually moves to S', it is likely that the equilibrium will move to E', which is the 'nearest available' new equilibrium to $E^{1}$. The second task is to direct the market from equilibrium $\mathrm{E}^{1}$ to $\mathrm{E}^{3}$. The latter is a pure coordination problem ${ }^{7}$. This explains why putting in a stimulus package to restore the original supply credit may not be sufficient to restore the original equilibrium equilibrium with plentiful supply of and demand for credit. Such an intervention would achieve the first policy task but not the second one, which would yield large dividends.

In the policy debate that has taken place thus far, there has been scant attention paid to the need for these two kinds of policy actions. This has hurt the efficacy of government policy, especially since two interventions require very different forms of action.

To increase the supply of credit, instead of the policy of rescuing all the banks that are making losses or the investment corporations that have taken a bad hit because of sub-prime lending or 'temporary nationalization' of all floundering banks that have been written about, it may be best to have one or two nationalized banks that deliberately lower the creditworthiness cut-off of potential borrowers and give out loans to them. This will of course entail incurring some fiscal cost but much less than helping all loss-making banks. As soon as there is one large bank giving out loans more liberally (by using a lower credit-worthiness cut-off), this will improve the lending environment of all lenders and encourage them to lend more. Hence, the supply correspondence will move down.

It is arguable that nations like India and China, where some banking is in the hands of public-sector banks, have seen a less severe financial crisis because of this reason. The presence of a few public-sector banks actually helped the private banks. In mid-2008 there was some anxiety that India may get into its own sub-prime crisis (Chandrasekhar, 2008). Structured finance whereby mortgages are pooled and sub-divided into CDOs, with tranches of different seniority, was happening in India. But such a crisis never took hold. There are many reasons for this but the presence of public sector banks was a factor.

It is also possible that the Reserve Bank of India's policy of raising the repo and reverse repo rates during the first three quarters of 2008, as part of inflation control measures (Lahiri,

\footnotetext{
${ }^{7}$ This should clarify that, even in the case where the exogenous decline in the supply of credit (mentioned at the start of this paragraph) were temporary, we may have a lasting impact of the amount of credit available on the market. This is because, the drop in supply (from $S^{\prime}$ to $S$ ) could send the market from $E^{3}$ to $E^{1}$, but the restoration of the supply back to $S^{\prime}$ may not lead the market back to $E^{3}$ but, instead, to $E^{\prime}$.
} 
2009), had an inadvertent beneficial effect. It limited the ability of lenders to indulge in the kind of recklessness seen in the U.S. and other industrialized nations, thereby dampening the exuberance that would almost inevitably be followed by a slump.

Once the supply correspondence $S^{\prime}$ is restored, a very different policy problem arises that has not been adequately addressed. The problem now is no longer that of changing some underlying feature, such as supply or demand, but of deflecting the economy from one equilibrium to another, in this case, from $E^{\prime}$ to $E^{3}$. Like all problems of coordination we do not really have a theory of how to select the equilibrium of our choice. Appealing to banks and financial organizations to lend more freely, as the U.S. government has done, may have some effect but is unlikely to galvanize serious action. An alternative is to create a very large stimulus package for a short-duration. There are analysts who have questioned the role of short-run interventions arguing that once such an intervention ceases the market will return to the 'bad' equilibrium. That is however not the case in economies with multiple equilibria. Once the good equilibrium is established and held onto by force for a while, it is arguable that the expectations of the private agents will change; so that even after that outside force is removed the equilibrium will remain there.

Suppose, in Figure 3, some state-sponsored or state-owned or state-subsidized banks lend so much more that the supply correspondence moves beyond S'.--So much so that the demand curve, D, has only one intersection with the new supply correspondence, which is to the right of $E^{3}$. As must be evident from the figure, for a sufficiently high supply correspondence the lowtransaction equilibrium will cease to exist.

With such a large stimulus package the economy will settle at a new equilibrium on the demand curve on the right hand side of $\mathrm{E}^{3}$ (the only available equilibrium). Then the state should slowly reduce the fiscally-promoted stimulus and let the supply correspondence drift back to S' or may be even further to the left, as long as there are two equilibria. There is reason to expect that, even though there are two equilibria, the economy once situated at the high-transactions equilibria, will remain there.

Since the large fiscal support needed to create a market situation in which there is only one equilibrium (with high credit transactions) will be a temporary measure, we do not have to worry about persistent fiscal drain and the consequent risk of inflation. 
There has been a proposal from some quarters that what is needed is to give the freemarket greater play by giving banks that lend money to people for buying homes the right to foreclose on not just the homes of the borrowers but also their bank accounts and other assets in the event of a default, in other words, to remove the provision of non-recourse from mortgage credit. It is true that this will make it more attractive for lenders to give loans and so is likely to increase the supply correspondence. But on the other hand, this will make borrowers more cautious and is likely to cause the demand for credit to move to the left. As the above figure makes it clear, the net effect of this is ambiguous. If the demand shift is greater than the supply shift this can actually exacerbate the problem. In fact, if this law is changed starting from the high-transactions equilibrium $\mathrm{E}^{3}$ in Figure 3, this can cause the equilibrium to disappear but causing the demand curve to move sharply left. So while it is true that this can help, it can also do harm. This is by no means a sure fire policy.

Given that the entire exercise in this paper is conducted in qualitative terms, it is not possible to go much further and specify the exact magnitudes of the interventions that will be needed to "get the job done". But the model provides a way of thinking about and conceptualizing this problem. Once this is backed up with some empirical work, it should be possible to make numerical calculations of the costs of both types of intervention-restoring multiple equilibria, and then deflecting the economy to the high-transactions equilibrium.

\section{Comments}

The model developed in this paper should be viewed as no more than a frame for conceptualizing the crisis. While there has already been a lot of theorizing on this ${ }^{8}$, the model presented in this paper has the advantage of simplicity. It provides a stark characterization of how a small credit correction can escalate into a major equilibrium shift with large changes in behavior, in this case, a sudden collapse in the supply of and demand for loans ${ }^{9}$. It is also distinct from existing models of collapse in lending, which are based on the idea of bubbles bursting.

\footnotetext{
${ }^{8}$ See, for instance, Allen and Carletti, 2008; Bebchuk and Goldstein, 2009; Brunermeier and Pedersen, 2009; Caballero and Simsek, 2009; He and Xiong, 2009.

${ }^{9}$ There are other more-sophisticated explanations that have been given in the literature of why people do not give or take loans in some situations. If, for instance, there is ambiguity aversion among individuals then, it can be shown, that this translates into a preference for not transacting (Easley and O'Hara, 2009). To use this to understand the present crisis would entail showing why such aversion may have got heightened in recent years.
} 
Despite the model's simplicity, it turns out to be a useful structure for raising and thinking about policy questions.

Nevertheless, several tasks remain to be done. The model mixes micro-theoretic and macro-theoretic arguments and the latter leaves open questions of micro-foundations. Consider, for instance, the function that describes the probability that credit will be repaid. This was given an intuitive characterization. It will be useful in the future to try to strengthen it with formal micro-foundations.

A second task is to check the actual empirical features of some of the general assumptions. What does the demand for credit function look like in particular contexts? What is the elasticity of demand in reality? Can we determine empirically some of the properties of the supply correspondence? To have answers to these will enable us to predict better which markets in reality are likely to be more vulnerable to small shocks translating into large changes in actual behavior and which markets will be robust and able to weather small shocks without big losses. As mentioned above, India had geared up for a home-grown credit crisis in 2008 but this never happened. Even though it is possible that large institutional and legislative factors, such as the nature of Indian banking regulation, were behind this, a better empirical understanding of India's demand function and supply correspondence of credit could shed additional light on this.

Finally, while I pursued some of the policy implications of this model, much more is possible. One can think of many other kinds of interventions, give them formal characterization, and then check out with the help of this model what their impacts are likely to be. The present paper merely skimmed the surface of such possibilities. 


\section{References}

Aghion, Philippe, Bacchetta, Philippe and Banerjee, Abhijit (2000), 'A Simple Model of Monetary Policy and Currency Crisis,' European Economic Review, vol. 44.

Akerlof, George and Shiller, Robert (2009), Animal Spirits: How Human Psychology Drives the Economy and Why it Matters for Global Capitalism, Princeton: Princeton University Press.

Allen, Franklin and Carletti, Elena (2008), 'The Role of Liquidity in Financial Crisis,' Jackson Hole Conference Proceedings, Federal Reserve Bank of Kansas City.

Basu, Kaushik (1991), 'The International Debt Problem, Credit Rationing and Loan Pushing,' Princeton Studies in International Finance 79.

Basu, Kaushik (2003), 'Globalization and the Politics of International Finance,' Journal of Economic Literature, vol. 41, 2003.

Basu, Kaushik (2009), ‘A Marketing Scheme for Making Money off Innocent People: A User’s Manual,' mimeo: Center for Analytic Economics, Cornell University.

Bebchuk, Lucian and Goldstein, Itay (2009), 'Self-fulfilling Market Freezes,' mimeo: Harvard Law School.

Besley, Tim and Coate, Stephen (1992), 'Understanding Welfare Stigma: Tax Payer Resentment and Statistical Discrimination,' Journal of Public Economics, vol. 48.

Bhaduri, Amit (1977), 'On the Formation of Usurious Interest Rates in Backward Agriculture,' Cambridge Journal of Economics, vol. 1.

Boorman, Jack (2009), 'The Current Financial Crisis: Its Origins, Its Impact, and the Needed Policy Response,' Global Journal of Emerging Market Economies, vol. 1, no. 2.

Brunnermeier, Markus (2009), 'Deciphering the Liquidity and Credit Crunch 2007-2008,' Journal of Economic Perspectives, vol. 23.

Brunnermeier, Markus and Pedersen, Lasse (2009), 'Market Liquidity and Funding Liquidity,' Review of Financial Studies, vol. 22, No. 6.

Caballero, Ricardo and Simsek, Alp (2009), 'Complexity and Financial Panics,' mimeo: MIT.

Chamley, Christophe (2003), Rational Herds: Economic Models of Social Learning, Cambridge: Cambridge University Press.

Chandrasekhar, C. P. (2008), 'India's Sub-prime Fears,' Economic and Political Weekly, vol. 
43, August 9.

Cline, W. (1984), International Debt: Systemic Risk and Policy Response, Cambridge, MA: MIT Press.

Coval, Joshua, Jurek, Jakub and Stafford, Erik (2009), 'The Economics of Structured Finance,' Journal of Economic Perspectives, vol. 23.

Diamond, Douglas and Dybvig, Philip (1983), 'Bank Runs, Deposit Insurance and Liquidity,' Journal of Political Economy, vol. 3.

Easley, David and O'Hara, Maureen (2009), 'Ambiguity and Nonparticipation: The Role of Regulation,' Review of Financial Studies, vol. 22. No. 5.

Haselmann, Rainer, Pistor, Katharina and Vig, Vikrant (2009), 'How Law Affects Lending,' Review of Financial Studies, forthcoming.

He, Zhiguo and Xiong, Wei (2009), 'Dynamic Bank Runs,' Mimeo: University of Chicago.

Hockett, Robert (2009), 'Bailouts, Buy-Ins, and Ballyhoo,' Challenge, vol. 52.

Hoff, Karla and Stiglitz, Joseph (2001), 'Modern Economic Theory and Development,' in Meier, G. M. and Stiglitz, J. E (eds.), Frontiers of Development Economics, New York: Oxford University Press.

Kiyotaki, Nobuhiro and Moore, John (1997), 'Credit Cycles,' Journal of Political Economy, vol. 5 .

Kotlikoff, Larry (2009), 'The Financial Fix: Limited Purpose Banking,' mimeo: Boston University.

Lahiri, Ashok (2009), 'Indian Financial Reforms: National Priorities Amidst an International Crisis,' text of the Purushottamdas Thakurdas Memorial Lecture, Mumbai.

Lin, Justin Yifu (2008), 'The Impact of the Financial Crisis on Developing Countries,' mimeo: The World Bank, Washington, D.C.

Lindbeck, Assar, Nyberg, Sten and Weibull. Jorgen (1999), 'Social Norms and Economic Incentives in the Welfare State,' Quarterly Journal of Economics, vol. 114.

Mayer, Christopher, Pence, Karen and Sherlund, Shane (2009), 'The Rise in Mortgage Defaults,' Journal of Economic Perspectives, vol. 23.

Ocampo, Jose Antonio (2009), 'Latin America and the Global Financial Crisis,' Cambridge Journal of Economics, forthcoming. 
Pence, Karen (2006), 'Foreclosing on Opportunity: State Laws and Mortgage Credit,' Review of Economics and Statistics, vol. 88.

Rakshit, Mihir (2008), 'The Subprime Crisis: A Primer,' Money and Finance, May.

Shiller, Robert (2000), Irrational Exuberance, Princeton: Princeton University Press.

Shin, Hyun Song (2009), 'Reflections on Northern Rock: The Bank Run that Heralded the Global Financial Crisis,' Journal of Economic Perspectives, vol. 23.

Subbarao, D. (2009), 'The Global Financial Turmoil and Challenges for the Indian Economy,' Reserve Bank of India Bulletin, vol. 58(1), January. 